\title{
Large eddy simulation of wind flow through an urban environment in its full-scale wind tunnel models
}

\author{
E. Reda $^{1,2}$, Rozli Zulkifli ${ }^{1}$ and Z. Harun ${ }^{1}$ \\ ${ }^{1}$ Faculty of Engineering and Built Environment, Universiti Kebangsaan Malaysia, \\ UKM Bangi, 43600, Selangor, Malaysia \\ ${ }^{2}$ Department of Mechanical Engineering, Alexandria University, Alexandria, Egypt \\ *Email: zambri@ukm.edu.my \\ Phone: +603 8912 6518; Fax: +603-8925-9659
}

\begin{abstract}
Wind flow through urban areas is studied either by wind tunnel scale experiments or via computational fluid dynamics simulations through full-scale actual models. The large difference between the Reynolds numbers based on the geometries of actual cities and wind tunnel scale cities makes the dynamic similarity between the two models uncertain. In this study, the mean and turbulent flow parameters were investigated using a large eddy simulation for two models i.e. the actual urban area model and the wind tunnel scale (1:1000) model. Kuala Lumpur City Centre, Malaysia, was considered as the case study of an urban area. Vertical velocity profiles were plotted at five locations representing different building packing densities. The results of wind tunnel scale model largely agreed with the actual model with some discrepancies in the building vicinity and wakes. The dissimilarity of the wake patterns due to the large difference in Re was responsible for the deviations. Largest discrepancies were found in the lateral and wall-normal velocity components and turbulence stresses. The results casted a shadow on the applicability of the conclusions derived from the simulations on wind tunnel scale models to the actual urban environments they represented. The deviation between the two models should be assessed before proceeding with experimental or numerical simulations on small-sized models.
\end{abstract}

Keywords: Dynamic similarity; LES; Atmospheric flow; turbulence; Wind tunnel model; full-scale model.

\section{INTRODUCTION}

One of the parameters that should be considered in the planning and development of modern cities is the air quality within the city. Insufficient ventilating mechanism could cause temperature rise and pollutant concentration which in turn result in health problems and increased power consumption by air conditioning systems usage $[1,2]$. In addition, the wind flow induces alternating lift and drag forces and hence causing vibrations on submerged buildings [3] that could potentially lead to failure of civil structures. Another factor motivating the research in atmospheric flow is the design of more efficient wind turbines [4]. The flow dynamics, heat dissipation and pollutant dispersion in urban areas can be obtained experimentally by on-site/wind-tunnel measurements or numerically by employing computational fluid dynamics (CFD) methods. As computer capabilities 
improve, CFD becomes more popular with its cost effectiveness and ability to test a wide variety of conditions [5-8].

Many wind tunnel experiments have been performed $[9,10]$ to investigate the wind flow through urban areas. Usually, the experiments were used to validate CFD simulation results of the same model size. The exact similarity between actual and wind tunnel models requires equality of governing equations i.e. equality of the dimensionless similarity parameters forming it (e.g. Reynolds, Rossby, Euler, Prandtl, Rayleigh, Peclet, Schmidt, Froude, and Eckert numbers) [11]. For flow through an urban area under neutral conditions and without pollutant dispersion, the only forces of concern are the inertia and viscous forces which are included in the Reynolds number $(\mathrm{Re})$. For example, in a tube heat exchanger, the pumping power decreases and the heat transfer enhances as the Reynolds number increases [12]. The problem with wind tunnel experiments is that the model has to be scaled-down by two or three orders of magnitude which requires a corresponding increase in flow speed to hold the dynamic similarity between the model and its prototype. This is almost impossible to be carried out because of mechanical and aerodynamic limitations. Fortunately, it is expected that at sufficiently high Reynolds numbers, the dynamic similarity becomes independent of Re [13].

The Reynolds number independence hypotheses have been examined for atmospheric flows by many authors over the past 60 years. The work of Golden stands as a landmark in the literature. Golden [14] measured the pollutant dispersion above the roof of idealised cubes in a wind tunnel. The researcher introduced a critical Reynolds number based on the building side length, of $\operatorname{Re}_{C}=11,000$ as a border just above where the concentration was independent of Reynolds number. The problem with Golden's work is that it focused on measuring one single parameter (concentration) at one single point (cube roof). Snyder [15] conducted an extensive review of the guidelines of wind tunnel modelling of atmospheric flows. According to him, the value of $\operatorname{Re}_{C}$ is a function of geometry, surface roughness and the parameter targeted from the simulation. Halitsky [16] argued that similarity can be assured in the wake region away from the building surface, at a $\operatorname{Re}_{C}$ as low as 3,000. Castro and Robins [17] measured the mean surface pressure of the flow over a cube under both uniform and boundary layer upstream conditions. They found that Reynolds number independence can be achieved above $\operatorname{Re}_{C}$ $=30,000$ under uniform flow and above $\operatorname{Re}_{C}=4,000$ under boundary layer flow. Generally speaking, rough surfaces exhibit lower critical Reynolds numbers [15]. After measurements of the wake region of different building geometries under different boundary layer flows were taken, it was concluded that the circulation region residence time and length became Reynolds number independent beyond $\operatorname{Re}_{C}=5,000$ [18]. It is noticed that turbulent stresses were totally not considered in the previous studies, despite their importance for heat and pollutant dispersion in urban areas. To the best knowledge of the authors, no researcher has examined the Reynolds number independence hypotheses for an actual complex urban environment with turbulent stresses as the main target parameters. The objective of this research is to build a link between the wind tunnel scale and the full-scale urban area CFD simulations i.e. to validate (or reject) the similarity between the wind tunnel scale urban models and the actual cities. In this research, the flow will be simulated in both a full-scale model and a wind tunnel scale urban area model. The comparison between the two models will reveal whether, and to what extent, the results obtained from a wind tunnel scale model could be applied to a full-scale city. This is supposed to help researchers assess the degree of precision offered by such prototype experiments and simulations. 


\section{METHODS AND MATERIALS}

\section{Geometrical Model Setup}

The actual model (AM) of Kuala Lumpur City Centre (KLCC) was generated using a combination between Google Earth® built-in models and the SketchUp® drawing tool. SketchUp was used to import Google Earth building models and modify them. They were imported automatically and accurately in their geographic locations relative to each other. The models not available on Google Earth were drawn manually by authors such as all buildings higher than $11 \mathrm{~m}$ within a 1800 -m diameter circle which were included in the simulation (see Figure 1). The origin of the axes was set at locations $\left(3^{\circ} 9\right.$ ' $10.83^{\prime}$ ' N, $101^{\circ} 42^{\prime} 40.49^{\prime}$ ' $\left.\mathrm{E}\right)$ and the $\mathrm{x}$ and $\mathrm{y}$ directions were taken as the wind-wise and windnormal direction as will be discussed in Section "Case Studies". The z-direction was taken as normal to the ground surface. The wind tunnel model (WTM) is a scaled-down (1:1000) model of KLCC. It is enclosed in a $1.8 \mathrm{~m}$ circle. Scales in the range (1:2001000) are common in the literature [19-21]. Both models were exported to STL files which can be readily handled by OpenFOAM, the CFD package used. In Figure 1, five points of interest (A, B, C, D and E) representing different packing densities have been considered. Point A, or simplified as $\mathrm{P}-\mathrm{A}$, represents an open area where high structures are located more than $100 \mathrm{~m}$ away. P-B, P-D and P-E represent moderate to high building density areas. Finally, P-C is closely surrounded by medium- to high-rise buildings from almost all sides.

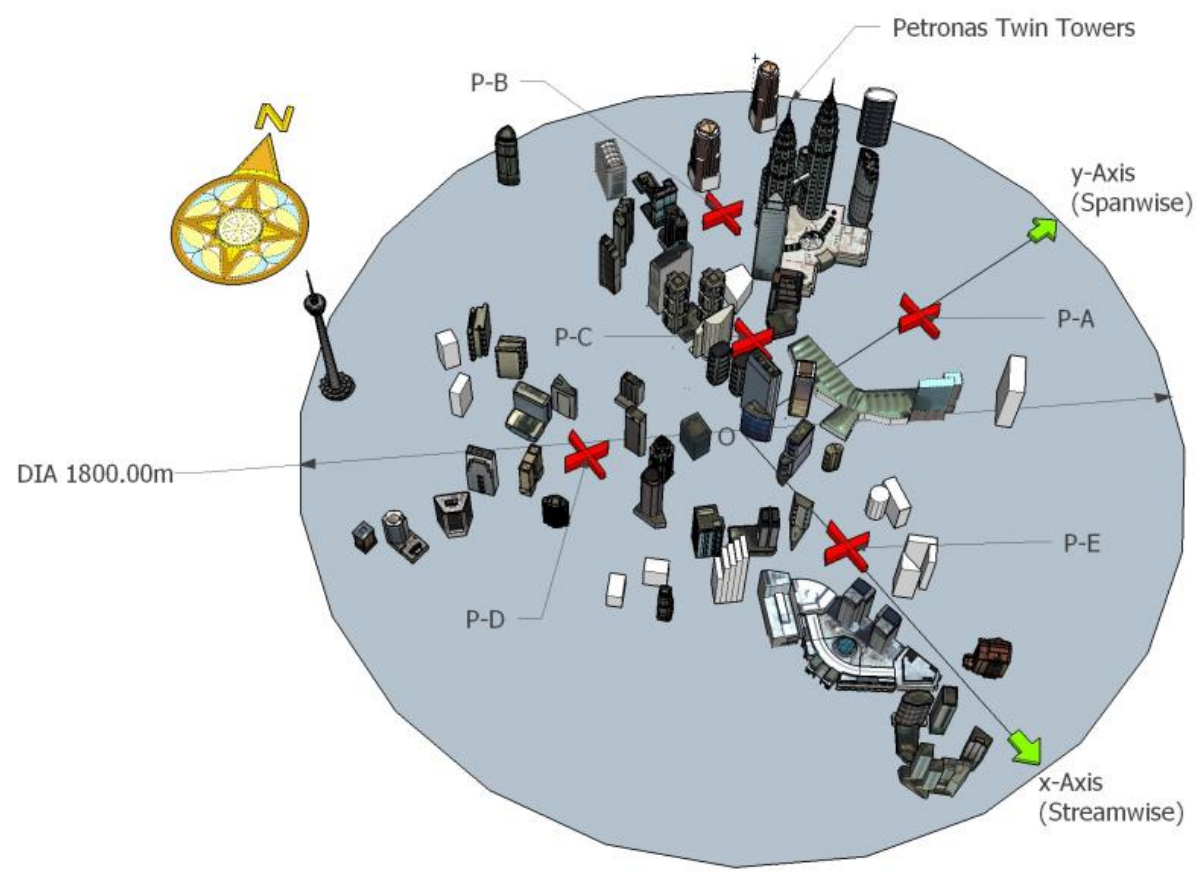

Figure 1. Actual KLCC model (AM).

\section{Mathematical Model Governing Equations}

Different turbulence models are used to simulate flow in urban areas. The LES is garnering an increasing popularity $[10,22-25]$ as an urban environment flow simulation model. This is due to its ability to accurately resolve turbulence stresses. In LES, a filter function is applied to the governing equations so that all fluctuations occurring on scales 
larger than the grid size are explicitly resolved (simulated) while smaller ones are modelled using the so-called subgrid-scale (SGS) models. The filtered continuity and momentum equations are listed below:

$$
\begin{gathered}
\frac{\partial \bar{u}_{i}}{\partial x_{i}}=0 \\
\frac{\partial \bar{u}_{i}}{\partial t}+\bar{u}_{j} \frac{\partial \bar{u}_{i}}{\partial x_{j}}=-\frac{1}{\rho} \frac{\partial \bar{p}}{\partial x_{i}}+v \frac{\partial^{2} \bar{u}_{i}}{\partial x_{j} \partial x_{j}}+\frac{\partial \tau_{i j}}{\partial x_{j}}
\end{gathered}
$$

In the present study, air was considered to be isothermal and incompressible [26] since the urban canopy lies in the bottom kilometer of the atmospheric boundary layer (ABL). The temperature was assumed to be constant and hence the fluid properties. In the above equations, the variables with overbars denote resolved scale quantities, $\bar{u}_{i}$ is the resolved-scale velocity component in the $x_{i}$ direction, $\bar{p}$ is the resolved scale pressure, $\rho$ is the fluid density, $v$ is the kinematic viscosity, and $\tau_{i j}$ is the subgrid stress. The subgrid stress was obtained by the dynamic Lagrangian model $[10,23]$. The details of the model can be found in [27].

\section{Boundary Conditions}

The boundary conditions need a special care in urban area flow simulation. The most important among them are probably the inlet and outlet boundary conditions. These two boundary conditions should be set such that three criteria are satisfied; (1) the application of the actual velocity profile at the inlet, (2) the horizontal homogeneity, i.e. the absence of horizontal gradients in the vertical profiles of the mean wind speed, and (3) the proper generation of turbulence for LES. The inlet and outlet boundaries were assigned periodic conditions $[10,22,28,29]$. In doing so, the flow properties calculated at the outlet in the previous iteration are to be assigned to the inlet in the new iteration as if the flow passes over an infinite rack of the simulated geometry. In this case, the flow needs to be forced by a pressure difference [28] or a fixed value velocity at the top boundary [29], as was used here. The lateral boundaries were assigned periodic conditions as well $[10,22,29$, 30]. The periodic boundary conditions were thought to be more suitable for KLCC since the selected business area is composed of a large number of random shapes and arrangement of buildings which are expected to efface the aerodynamic features of individual buildings. The domain was set long enough $(1800 \mathrm{~m})$ to minimise transfer of the aerodynamic fingerprint of the model through consecutive iterations. This can be assured by reviewing the horizontal profiles of the mean velocity components illustrated in Section "Mean Velocity and Turbulent Stress Profiles". Generally, all profiles show zero gradient at the horizontal boundaries. For both actual and idealised models, the ground and building walls were assigned a no-slip condition and wall functions were used to calculate the turbulent kinetic energy at the wall nearest to the grid point $[31,32]$. The surface roughness height $\left(\mathrm{z}_{0}\right)$ was taken as $0.1 \times 11 \mathrm{~m}$ in $\mathrm{AM}$ and $0.1 \times 11 \mathrm{~mm}$ in WTM [33].

\section{Computational Domain and Mesh Generation}

The COST Action 732 [34] guided the design of the computational domain in both models. For AM, knowing the average building height is $122 \mathrm{~m}$ and the maximum height is $451.9 \mathrm{~m}$ and the plan area of the building block is $1670 \times 1500 \mathrm{~m}^{2}$, the domain height was extended to $1500 \mathrm{~m}$ above the ground level and its plan area was set to $1800 \times 1650$ $\mathrm{m}^{2}$. For WTM, the whole domain size was set to $1.8 \times 1.65 \times 1.5 \mathrm{~m}^{3}$. Both models were 
introduced to OpenFOAM in the STL format and the mesh was generated using the snappyHexMesh tool. Two meshes were used for AM for the sake of grid dependency analysis; AM and AM-Fine (AMF) which has $\sim 60 \%$ more cells than AM. The snappyHexMesh tool produced similar meshes for both models due to the geometrical similarities of these models.

Figure 2 compares the vertical profiles of mean and turbulent velocity components for AM and AMF models at points A-E. Generally, it can be said that the solution is grid independent; however, large discrepancies can be noticed in the spanwise mean velocity at $\mathrm{B}$ and $\mathrm{C}$ (Figure2(c)), in the spanwise turbulent intensity at $\mathrm{C}$ (Figure 2(d)) and in the vertical mean velocity at B (Figure 2(e)). These can be attributed to the large cell size used in these areas. Recalling the target of this research to compare two geometrically similar models of different scales but with the same mesh structure, these deviations did not affect the integrity of the research results.

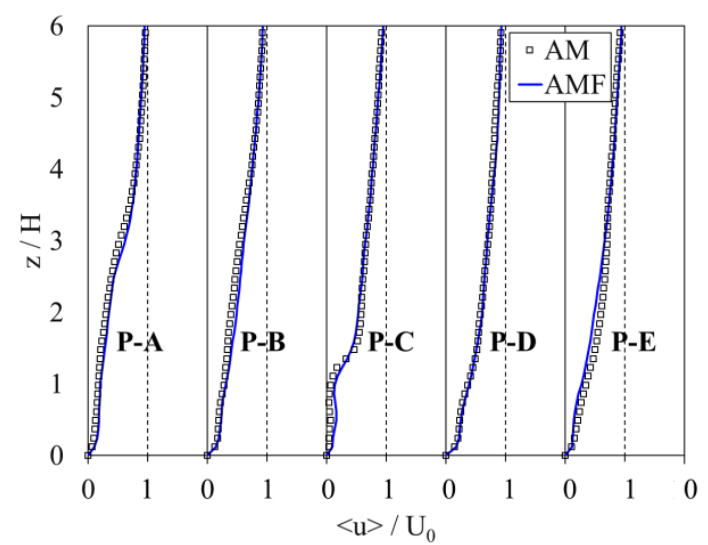

(a)

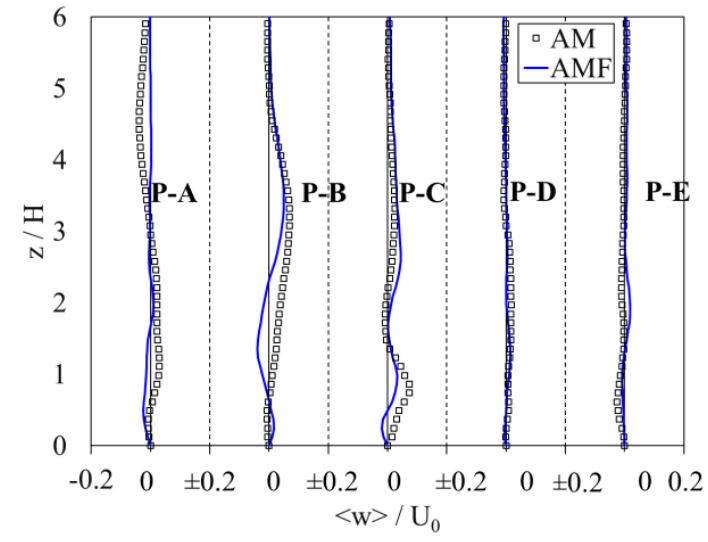

(c)

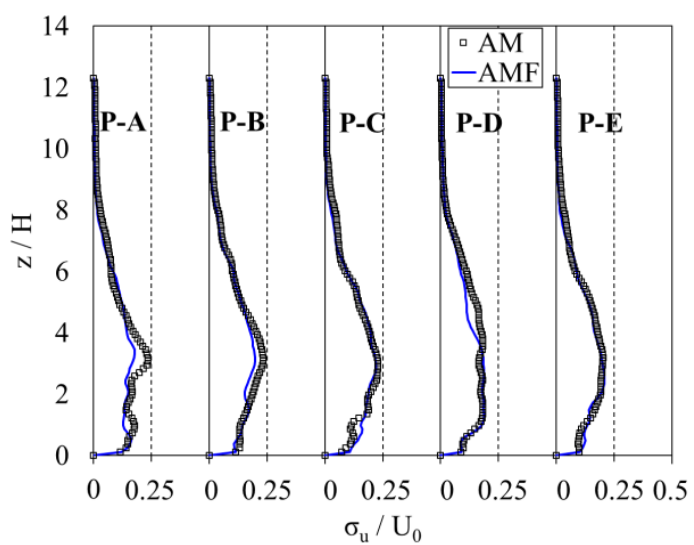

(b)

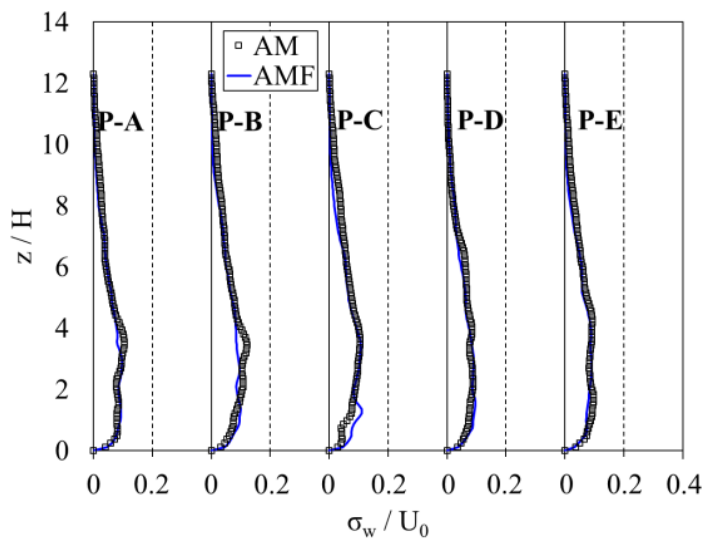

(d)

Figure 2. Grid dependence analysis of AM. Comparing the mean and turbulent velocity components for AM and AMF (AM-Fine). The profiles are drawn along $5 \mathrm{z}$-axes passing through points (A, B, C, D, and E). All velocity components are normalised by $\mathrm{U}_{0}$.

\section{Case Studies}

The magnitudes of wind speed were obtained by analysing the upper air sounding data of the Wyoming University. The selected data were captured at Sepang ( $\sim 56 \mathrm{~km}$ to the south of KLCC), at the average ABL height of $1000 \mathrm{~m}$ above ground level $( \pm 100 \mathrm{~m})$, twice per 
day; at 8 am and 8 pm (local time) over ten years (2004-2014). Based on this analysis, not shown here, the free stream velocity was set to $U_{0}=5 \mathrm{~m} / \mathrm{s}$, its direction is the NorthWest direction and the whole domain temperature was fixed at $21^{\circ} \mathrm{C}$. These figures agree well with the data analysis carried out by [35]. The selected wind speed and fluid properties resulted in a value of $\mathrm{Re}$, based on $\mathrm{H}$, of $4.01 \times 10^{7}$ in $\mathrm{AM}$ and $4.01 \times 10^{4}$ in WTM. The direction of the wind selected here, however did not match seasonal monsoon winds; neither the hot dry South Westerly monsoon (June-September) nor the wet cold North Easterly monsoon (December-February) [36].

\section{Solution Technique}

As mentioned earlier, the OpenFOAM, an open source CFD package was used [28] to solve the problem. The pressure-velocity coupling was maintained by the PISO algorithm [37]. Both models were initiated with a uniform velocity of U0 in the streamwise direction and zero subgrid stress. The simulation lasted for 15 turnovers, $15 \times$ domain length $/ \mathrm{U}_{0}$, such that the change in mean or turbulent velocity was less than $5 \%$ per turnover. Five turnovers were devoted for flow development and 10 for averaging. The time steps considered were $2 \times 10^{-2} \mathrm{~s}$ and $2 \times 10^{-5} \mathrm{~s}$ for AM and WTM, respectively.

\section{Validation of the Results}

The conclusions were examined by simulating the flow in an idealised city model with the experimental data. The data selected belong to [38] who simulated the flow through an idealised urban structure experimentally in a wind tunnel, and numerically via LES. The studied model (Exp) was composed of four boxes of dimensions $500 \times 750 \mathrm{~mm}$ and building height $\mathrm{H}=125 \mathrm{~mm}$. Roughness elements (rectangular plates of height $25 \mathrm{~mm}$ ) were also placed in the upstream of the model in a staggered arrangement. The boundary layer had a roughness length $\mathrm{z} 0=1.5 \mathrm{~mm}$ and free stream velocity $\mathrm{U}_{0}=2.5 \mathrm{~m} / \mathrm{s}$. The Reynolds number (based on $\mathrm{H}$ ) was found to be 20,000. In the present research, the flow was simulated through an identical wind tunnel scale model (WTS) and a 1000:1 fullscale model (FS). LES was implemented with the dynamic Lagrangian model as an SGS model. A uniform-velocity inlet, zero-gradient outlet, no-slip ground and walls, zerogradient top and symmetry lateral walls boundary conditions were used in the simulation. One row of roughness elements was found to be enough to produce the required turbulence in the blowing flow. The solution was initiated with a uniform streamwise velocity of $2.5 \mathrm{~m} / \mathrm{s}$ and zero subgrid stress. The total simulation period was set to 22 seconds (22,000 seconds for FS) which allowed the flow to sweep the domain 15 times, with only the last 10 of them included in the averaging process. Although the domain height in the CFD simulation of [38] was $500 \mathrm{~mm}$, the height set in this study was 1500 $\mathrm{mm}(1500 \mathrm{~m})$. This is considered to comply with the COST Action 732 which recommends a $3 \%$ flow blockage area whereas in [38], it is more than 13\%. The high blockage area introduced an artificial acceleration to the flow and subjected the model to higher streamwise velocity. Another difference from [38] was the use of logarithmic wall functions with a roughness length $\mathrm{z} 0=1.5 \mathrm{~mm}(1.5 \mathrm{~m})$ at ground and building walls.

\section{RESULTS AND DISCUSSION}

\section{Mean Velocity and Turbulent Stress Profiles}

Figures 3 and 4 compare the mean velocity and turbulence parameters between AM and WTM for $\mathrm{x}, \mathrm{y}$ and $\mathrm{z}$ axes at different points, all normalised by the free stream velocity $\mathrm{U}_{0}$. DL and DW are the full domain length $(1800 \mathrm{~m})$ and width $(1650 \mathrm{~m})$, respectively. 
As can be observed in these figures, the mean velocity and turbulent stress values obtained from the wind tunnel model (WTM) largely agreed with those of the prototype (AM). This was expected from the literature, especially at the high Reynolds numbers considered [14-17]. However, there were some minor inconsistencies in two groups of data. The first group was composed of the vertical profiles at points $\mathrm{B}$ and $\mathrm{C}$ (or P-B and P-C in Figure 1). Despite the agreement in streamwise mean and turbulent velocities (Figures 3(a) and 4(a)), the spanwise (not shown here) and the vertical (Figures 3(c) and 4(c)) components slightly deviated between the two models. Because of the deviations in $\sigma_{v}$ and $\sigma_{w}$, the turbulent transport stresses, $\left\langle u^{\prime} v^{\prime}\right\rangle$ and $\left\langle w^{\prime} u^{\prime}\right\rangle$ were affected as well (Figures 4(b) and 4(d)). The second discrepancy group was made up of deviations along the $\mathrm{x}$ and $\mathrm{y}$ axes. The group included deviations in both $\langle u\rangle$ (Figure 3(b)) and $\langle w\rangle$ (Figure 3(d)) along the $\mathrm{x}-\mathrm{A}$ axis $(-0: 1<x=D L<0: 2)$, along the $\mathrm{x}-\mathrm{D}$ axis $(-0: 4<x=D L$ $<-0: 2)$ and along the $\mathrm{x}-\mathrm{E}$ axis $(-0: 1<x=D L<0)$.

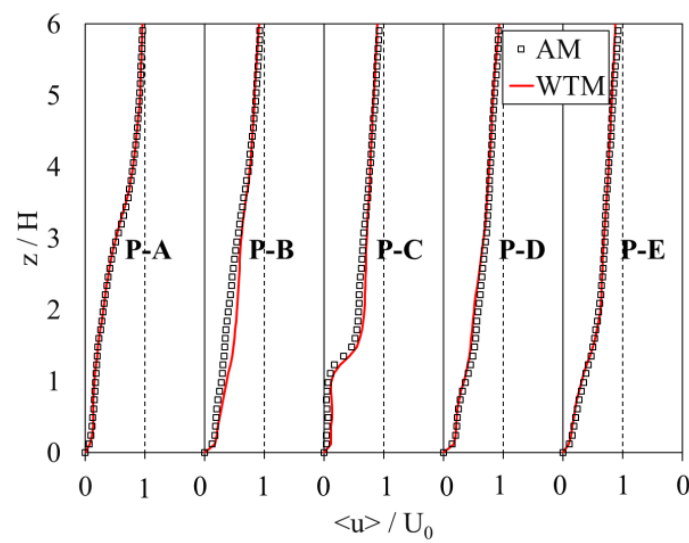

(a)

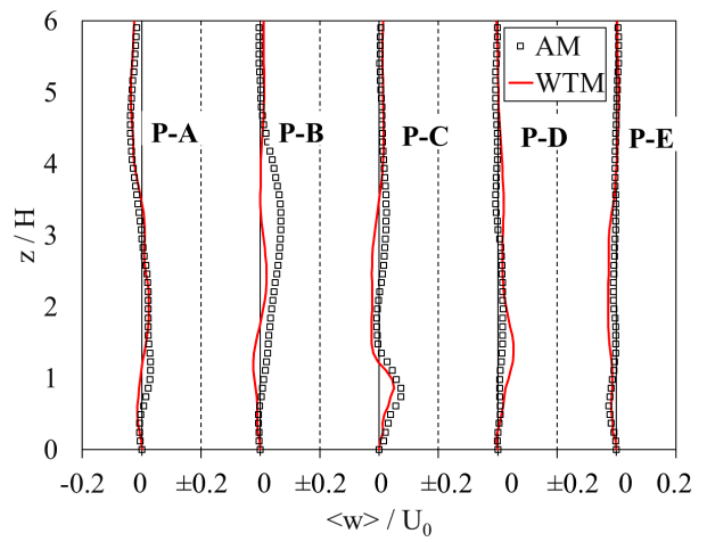

(c)

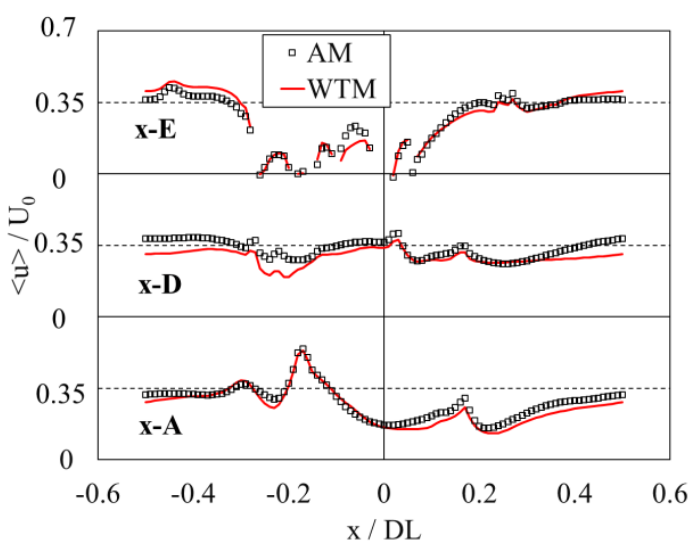

(b)

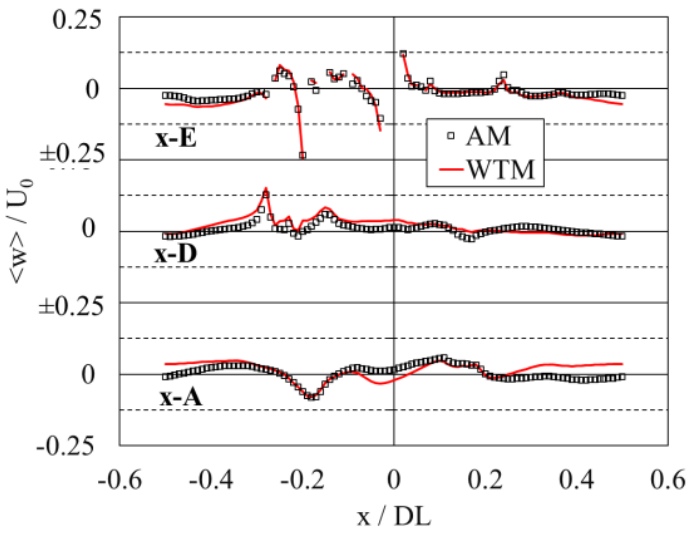

(d)

Figure 3. Comparing the WTM mean velocity distribution parameters with AM. The profiles were drawn along $3 \mathrm{x}$-axes, $3 \mathrm{y}$-axes and $5 \mathrm{z}$-axes passing through points (A, D, $\mathrm{E}),(\mathrm{B}, \mathrm{C}, \mathrm{E})$ and $(\mathrm{A}, \mathrm{B}, \mathrm{C}, \mathrm{D}, \mathrm{E})$, respectively. The $\mathrm{x}$ and $\mathrm{y}$ axes were considered to lie at $\mathrm{H}$ height above ground. All velocities were normalised by $\mathrm{U}_{0}$.

These deviations could not simply be attributed to the short simulations periods. The common factor between the deviations is that they all occur in the vicinity or wake of buildings e.g. point $\mathrm{C}$ is surrounded by high-rise buildings from every side. Figure 5 shows the streamlines of the flow through AM and WTM at $\mathrm{z}=\mathrm{H}$ at three different locations; namely the Petronas Twin Towers wake, the origin (close to point $\mathrm{C}$ ) and at 
point D. The figure interpreted the deviation between AM and WTM. The wake vortices were not always the same in AM and WTM; sometimes WTM showed stronger wake vortices (Figures 5(a) and 5(b)). Besides, the velocity or turbulence distribution can differ at certain locations (Figures 5(c) and 5(d)). It was thought that the large difference in Re caused the building wakes in the two models to lie in different wake regimes. The wake evolution with Re is a well-established phenomenon in the flow past immersed bodies [39]. Consequently, neither the mean nor the turbulent flow properties will be the same in these areas.

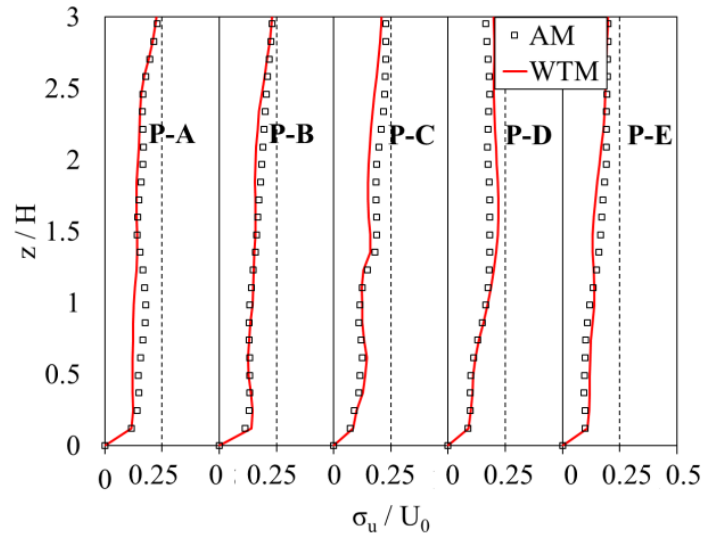

(a)

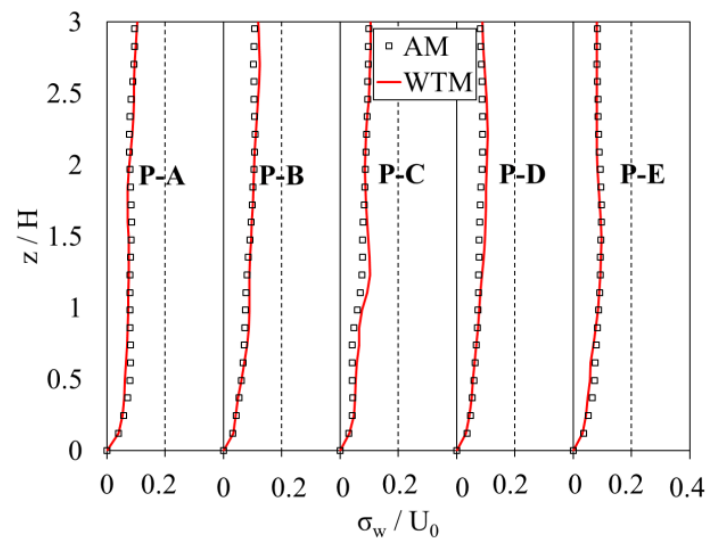

(c)

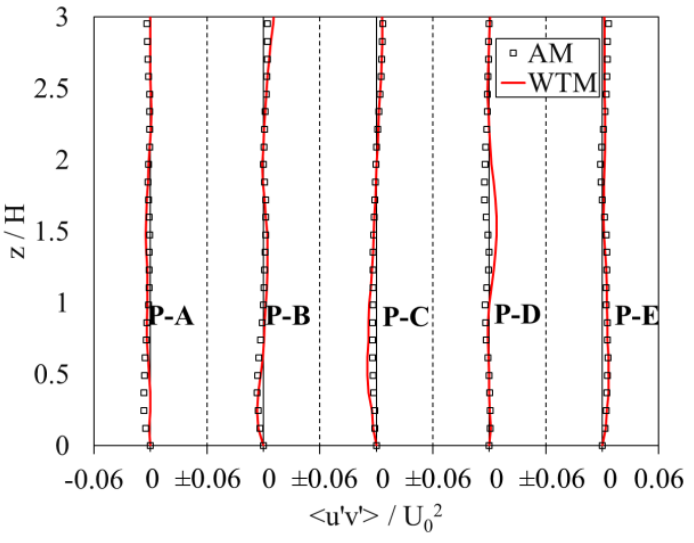

(b)

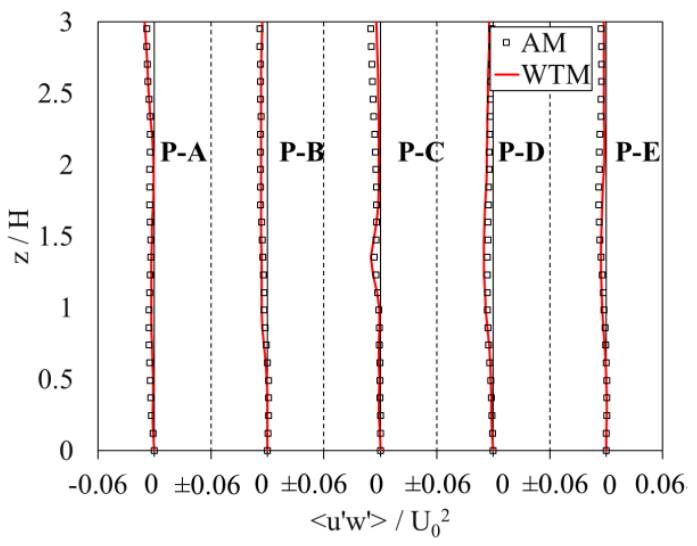

(d)

Figure 4. Comparing the WTM turbulent stresses with AM. The profiles were drawn along 3 x-axes, 3 y-axes and 5 z-axes passing through points (A, D, E), (B, C, E) and ( $\mathrm{A}, \mathrm{B}, \mathrm{C}, \mathrm{D}, \mathrm{E})$, respectively. The $\mathrm{x}$ and $\mathrm{y}$ axes were considered to lie at $\mathrm{H}$ height above ground. All velocity fluctuations were normalised by $\mathrm{U}_{0}$.

The conflict between the current conclusions and the solid dynamic similarity theory [14-17] has to be clarified. One reason of the conflict is the difference in the parameters under study. While the previous studies focused on pollutant concentrations, the current research explored deep into the dispersive turbulent stresses. According to Xie and Castro [40], the pollutant dispersion is not sensitive to the turbulence generation method in CFD simulations. Another reason is the difference in geometry of the urban environment under consideration. The idealised models provide more uniformity in the flow and efface the flow structures of the individual buildings [41, 42]. A third source of the apparent contradiction is the difference in the measurement locations. For instance, 
the volume of air within a street canyon is well mixed compared to the above-roof level [43].

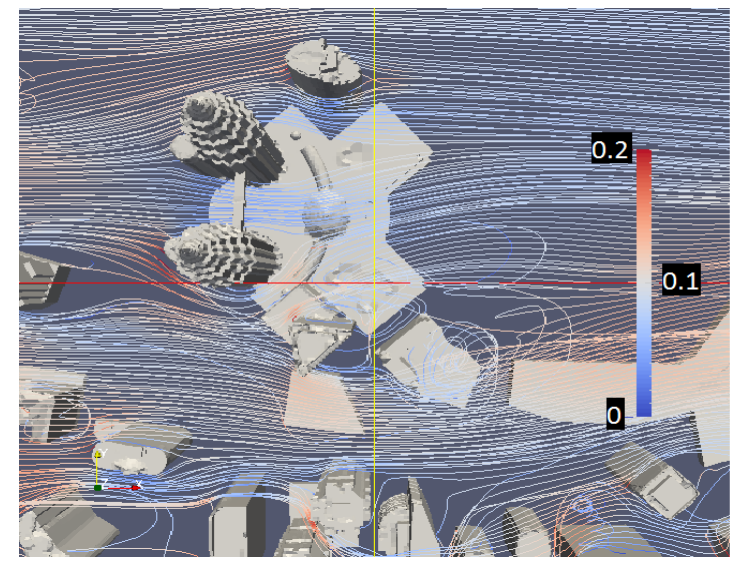

(a)

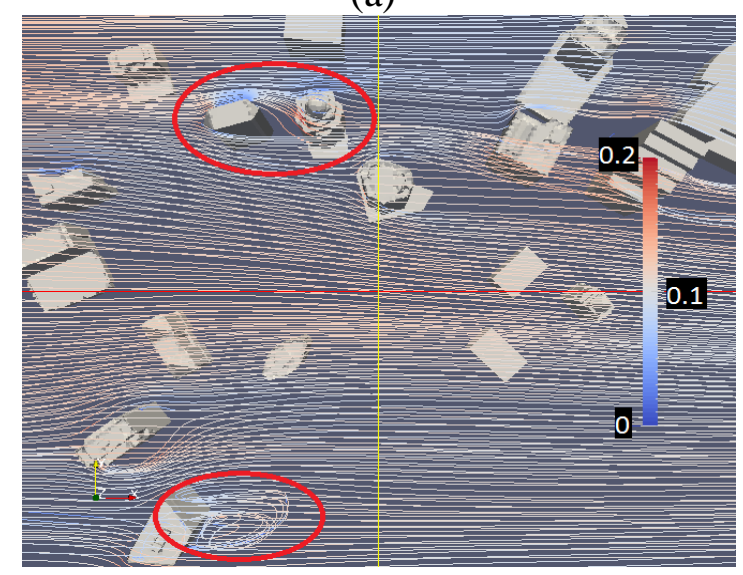

(c)

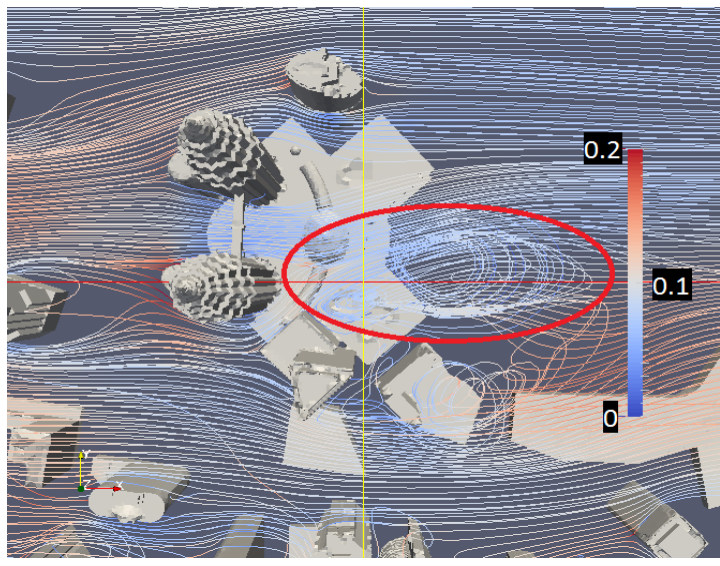

(b)

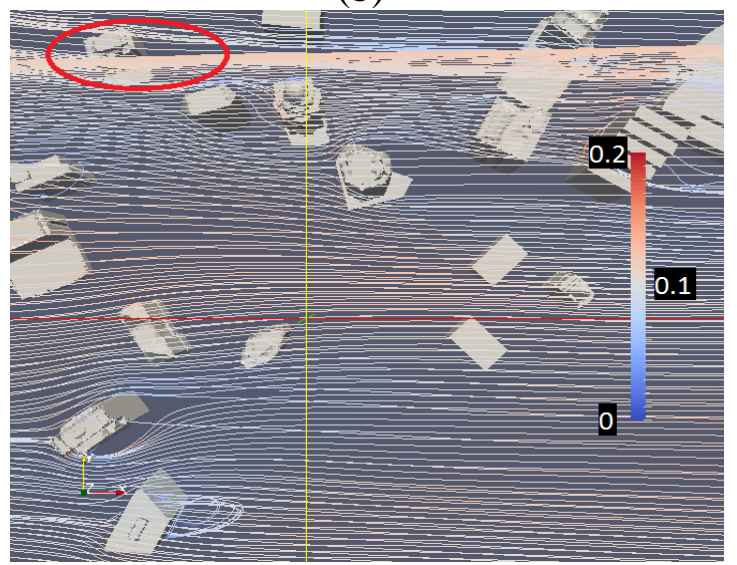

(d)

Figure 5. Streamlines of the flow through AM (left) and WTM (right) at $\mathrm{z}=\mathrm{H}$, coloured by $\sigma_{\mathrm{v}}=\mathrm{U}_{0}$; top: wake of the Petronas Twin Towers, middle: the origin (close to point $\mathrm{C}$ ), bottom: point $\mathrm{D}$.

A prevailing agreement can be noticed between CFD results (WTS) and the experimental data (Exp) in both trends and values (Figures 6 and 7). Although there was a minor discrepancy $(\sim 0.1 \mathrm{~m} / \mathrm{s})$ in the streamwise mean velocity along $\mathrm{y}=0$ axis at $\mathrm{z}=$ H/2 (Figure 6(b)), the remaining results (Figures 6(a), 6(c) and 6(d)) still showed good agreement. For the spanwise velocity component, the values along $x=0$ axis at $z=H / 4$ (Figure 7(a)) fit the measurements. Finally, the root mean square (R.M.S.) of spanwise velocity fluctuation followed the trend of experimental data with a maximum deviation of $0.1 \mathrm{~m} / \mathrm{s}$ along $\mathrm{y}=0$ axis at $\mathrm{z}=\mathrm{H} / 2$ (Figure $7(\mathrm{~b})$ ). The prominence of the [38] data is its focus on the near field region around buildings. Despite the harmony of trends between both models, the FS values generally deviates from WTS predictions. The deviations concentrate in the streamwise street between the buildings. This is thought to be due to the difference in boundary layer size and characteristics in both models [44]. Another difference can be noticed in Figure 8; the wake regions for roughness elements as well as the main buildings were shorter in the case of FS. It is obvious that the wake regions for both models lie in different regimes which were reflected on the vortex strength in each case in Figure 9. 

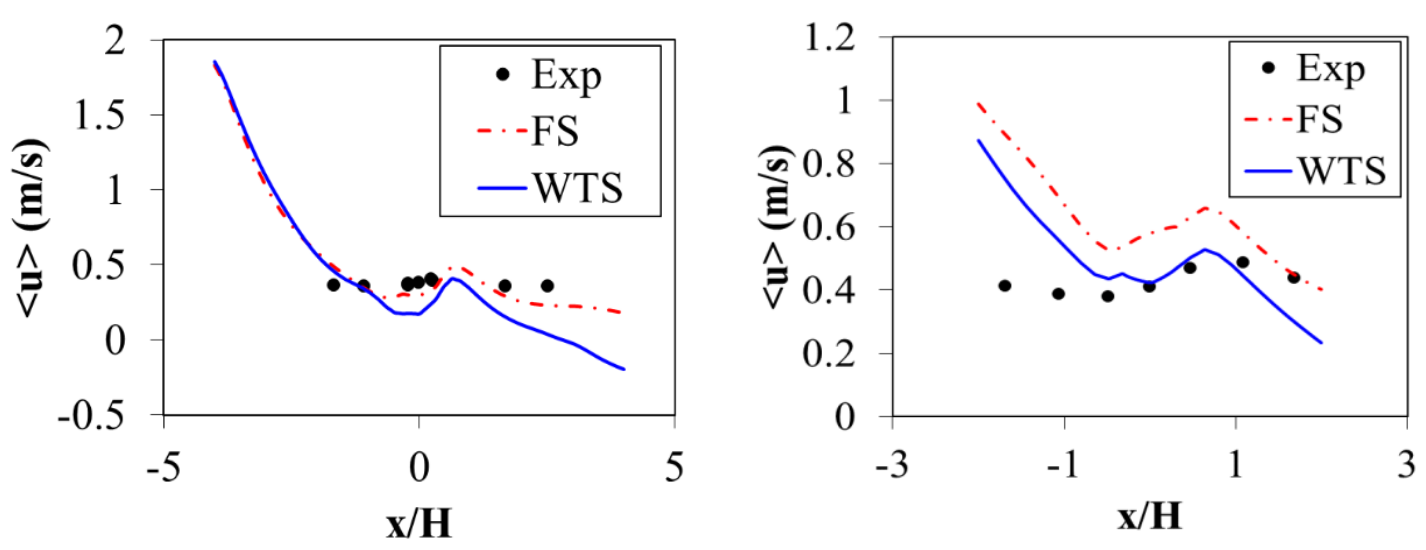

(a) $\mathrm{y}=0, \mathrm{z}=\mathrm{H} / 4$

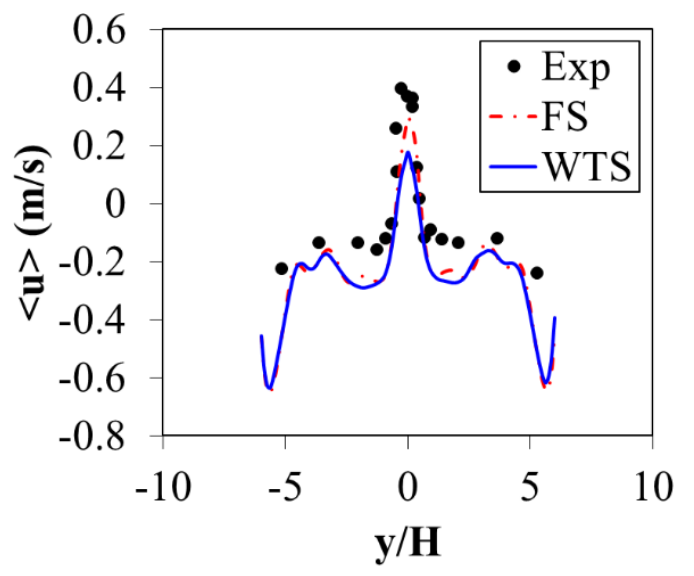

(b) $y=0, z=H / 2$

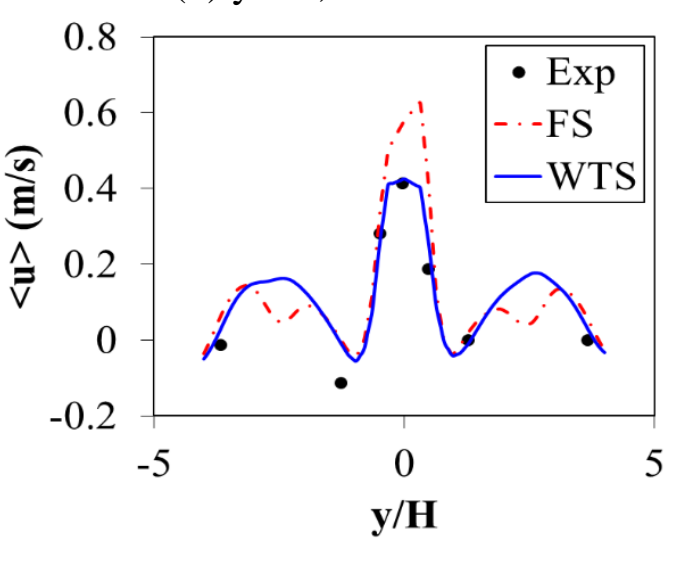

(c) $x=0, z=H / 4$

(d) $x=0, z=H / 2$

Figure 6. Validation of numerical setup; mean streamwise velocity component.

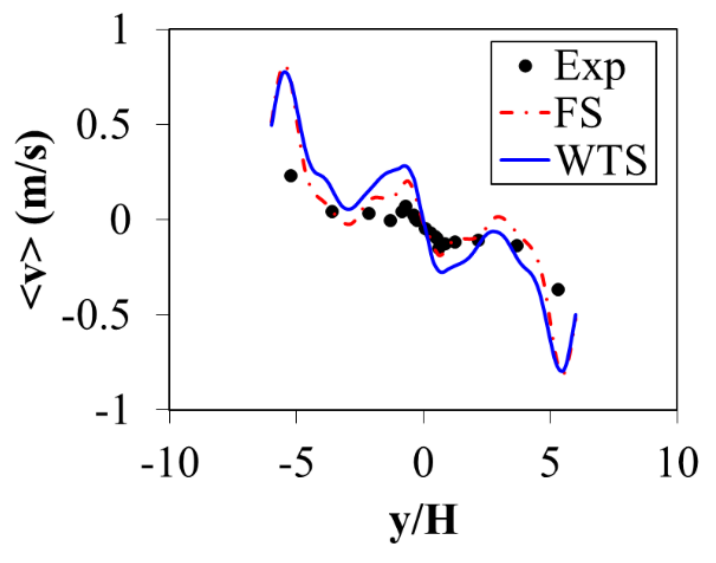

(a) $x=0, z=H / 4$

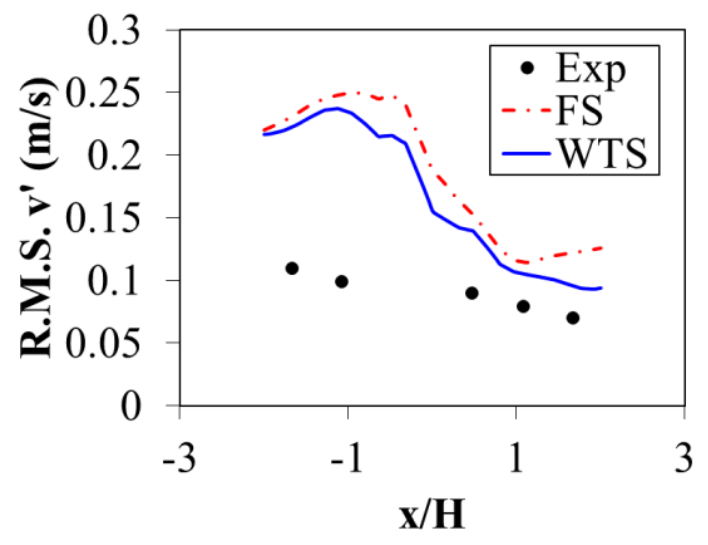

(b) $y=0, z=H / 2$

Figure 7. Validation of numerical setup; mean and R.M.S value of spanwise velocity component. 


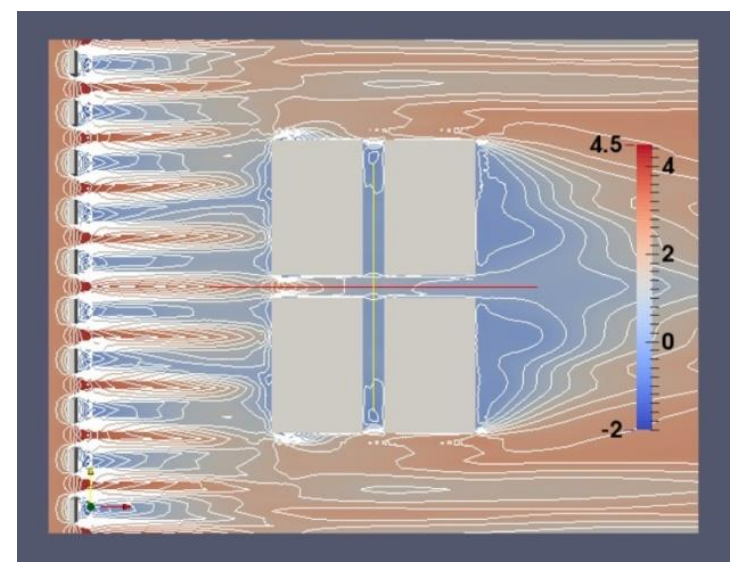

(a)

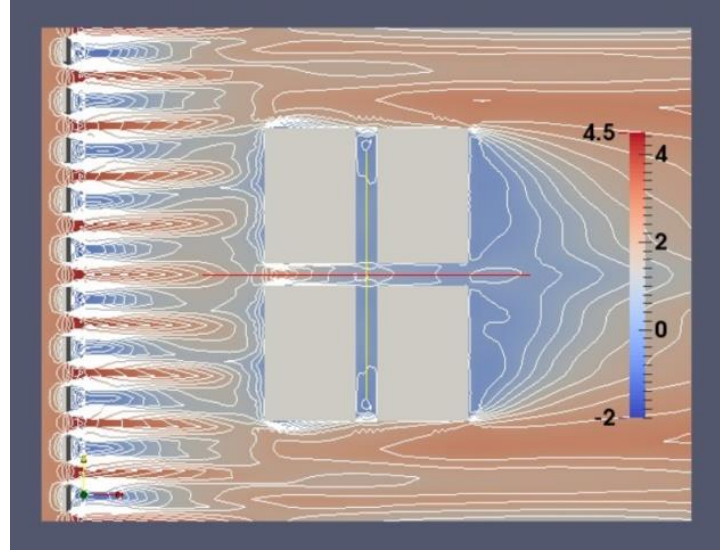

(b)

Figure 8. Velocity contours of the flow through the validation model; FS (left) and WTS (right). Coloured by mean streamwise velocity $(\mathrm{m} / \mathrm{s})$.

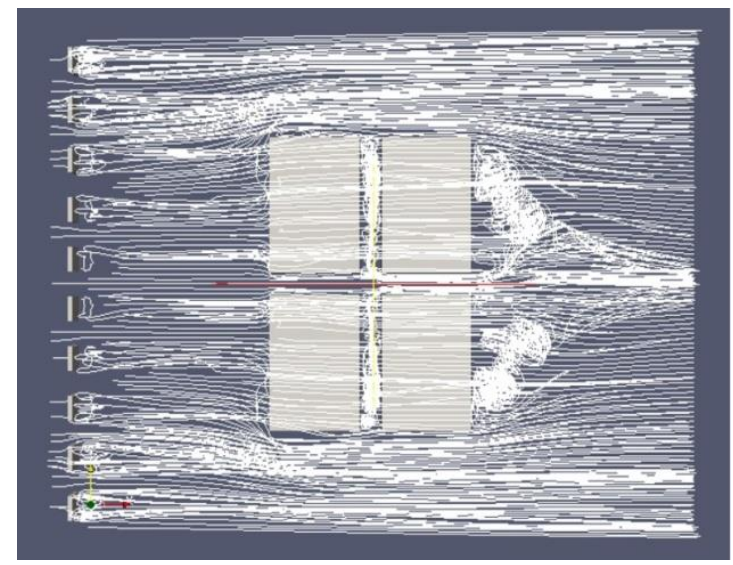

(a)

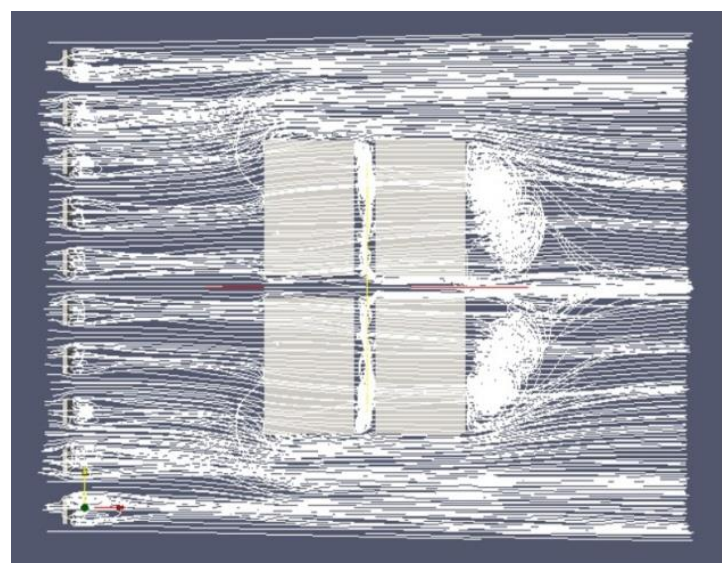

(b)

Figure 9. Streamlines of the flow through the validation model; FS (left) and WTS (right).

\section{CONCLUSIONS}

Although many of the ventilation characteristics in urban areas are deduced from experimental and CFD simulations on wind tunnel scale models, there is no strong evidence of the applicability of these characteristics towards the full-scale cities. In the present work, wind flow was simulated via LES through KLCC in its actual full-scale model (AM) and wind tunnel scale model (WTM). The results of the WTM were found to be largely in agreement with AM for both mean and turbulent parameters. Nonetheless, there were minor discrepancies in the values rather than the trends, especially in building vicinities and wake regions. The discrepancies were concentrated in the cross-wind and wall-normal velocity components and turbulent stresses. Furthermore, the vortical structure in the wake of the buildings differed at many spots. For example, some wake vortices disappeared between the two models. These were attributed to the large difference in Re numbers between the two models which caused their respective building wakes to lie in different regimes. This puts a question mark over the eligibility of wind tunnel scale experiments and simulation of the heat transfer or mass dispersion in these 
areas. The conclusions were validated with the experimental work of [38] through a fourblock idealised city model. The comparison between the wind tunnel scale (WTS) and full-scale (FS) models revealed weaker vortical structures in the FS model. This research must be extended to obtain quantitative estimations of the discrepancies and suggest corrective correlations. Researchers holding experimental or CFD analysis on wind tunnel models are recommended to assess the deviation between the full and wind tunnel scale models for the studied parameters at the considered locations.

\section{ACKNOWLEDGEMENTS}

The authors would like to thank Universiti Kebangsaan Malaysia for the Research University Grants (DIP-2015-006)) and the Ministry of Education for the Exploratory Research Grant (ERGS/1/2013/TK01/UKM/03/2).

\section{REFERENCES}

[1] Muhsin F, Yusoff WFM, Mohamed MF, Sapian AR. Cfd modeling of natural ventilation in a void connected to the living units of multi-storey housing for thermal comfort. Energy and Buildings. 2017;144:1-16.

[2] Akeiber H, Nejat P, Majid MZA, Wahid MA, Jomehzadeh F, Famileh IZ, et al. A review on phase change material $(\mathrm{pcm})$ for sustainable passive cooling in building envelopes. Renewable and Sustainable Energy Reviews. 2016;60:1470-97.

[3] Rahman MAA, Thiagarajan KP. Experiments on vortex-induced vibration of a vertical cylindrical structure: Effect of low aspect ratio. International Journal of Automotive and Mechanical Engineering. 2015;11:2515-.

[4] Al-Faruk A, Sharifian AS. Effects of flow parameters on the performance of vertical axis swirling type savonius wind turbine. International Journal of Automotive and Mechanical Engineering. 2015;12:2929-43.

[5] Wahhad AM, Adam NM, Sapuan SM. Comparison of numerical simulation and experimental study on indoor air quality of air-conditioned office building in desert climate. International Journal of Automotive and Mechanical Engineering. 2015;12:3109-24.

[6] Rasani MR, Aldlemy MS, Harun Z. Fluid-structure interaction analysis of rear spoiler vibration for energy harvesting potential. Journal of Mechanical Engineering and Sciences. 2017;14:2415-27.

[7] Tahseen TA, Ishak M, Rahman MM. Laminar forced convection heat transfer over staggered circular tube banks: A CFD approach. Journal of Mechanical Engineering and Sciences. 2013;4:418-30.

[8] Tahseen TA, Ishak M, Rahman MM. A numerical study of forced convection heat transfer over a series of flat tubes between parallel plates. Journal of Mechanical Engineering and Sciences. 2012;3:271-80.

[9] Gousseau P, Blocken B, Stathopoulos T, Van Heijst GJF. Cfd simulation of nearfield pollutant dispersion on a high-resolution grid: A case study by les and rans for a building group in downtown montreal. Atmospheric Environment. 2011;45:428-38.

[10] Sun L, Nottrott A, Kleissl J. Effect of hilly urban morphology on dispersion in the urban boundary layer. Building and Environment. 2012;48:195-205. 
[11] Yuan R, Wu X, Luo T, Liu H, Sun J. A review of water tank modeling of the convective atmospheric boundary layer. Journal of Wind Engineering and Industrial Aerodynamics. 2011;99:1099-114.

[12] Tahseen TA, Rahman MM, Ishak M. Effect of tube spacing, fin density and reynolds number on overall heat transfer rate for in-line configuration. International Journal of Automotive and Mechanical Engineering. 2015;12:306575.

[13] Townsend AA. The structure of turbulent shear flow: Cambridge university press; 1956.

[14] Golden J. Scale model techniques. 1961.

[15] Snyder WH. Guideline for fluid modeling of atmospheric diffusion: Environmental Sciences Research Laboratory, Office of Research and Development, US Environmental Protection Agency; 1981.

[16] Halitsky J. Gas diffusion near buildings ch. 5-5 of meteorology and atomic energy. US Atomic Energy Commission TID-24190 Oak Ridge; 1968. p. 221-55.

[17] Castro IP, Robins AG. The flow around a surface-mounted cube in uniform and turbulent streams. Journal of Fluid Mechanics. 1977;79:307-35.

[18] Fackrell JE, Pearce JE. Parameters affecting dispersion in the near wake of buildings. Central Electricity Generating Board. 1981.

[19] Ricci A, Kalkman I, Blocken B, Burlando M, Freda A, Repetto MP. Impact of model parameters on 3d-steady state rans simulations of urban wind flow: The case study of livorno city. XIV Conference of the Italian Association for Wind Engineering; 2016.

[20] Jedrzejewski M, Pocwierz M, Zielonko-Jung K. The problem of airflow around building clusters in different configurations. Archive of Mechanical Engineering. 2017;64:401-18.

[21] Ramponi R, Blocken B. Cfd simulation of cross-ventilation flow for different isolated building configurations: Validation with wind tunnel measurements and analysis of physical and numerical diffusion effects. Journal of Wind Engineering and Industrial Aerodynamics. 2012;104:408-18.

[22] Kikumoto H, Ooka R. A numerical study of air pollutant dispersion with bimolecular chemical reactions in an urban street canyon using large-eddy simulation. Atmospheric Environment. 2012;54:456-64.

[23] Liu YS, Miao SG, Zhang CL, Cui GX, Zhang ZS. Study on micro-atmospheric environment by coupling large eddy simulation with mesoscale model. Journal of Wind Engineering and Industrial Aerodynamics. 2012;107:106-17.

[24] Liu J, Srebric J, Yu N. Numerical simulation of convective heat transfer coefficients at the external surfaces of building arrays immersed in a turbulent boundary layer. International Journal of Heat and Mass Transfer. 2013;61:20925.

[25] Wyszogrodzki AA, Miao S, Chen F. Evaluation of the coupling between mesoscale-wrf and les-eulag models for simulating fine-scale urban dispersion. Atmospheric Research. 2012;118:324-45.

[26] Stull RB. An introduction to boundary layer meteorology: Springer Science \& Business Media; 1988.

[27] Meneveau C, Lund TS, Cabot WH. A lagrangian dynamic subgrid-scale model of turbulence. Journal of Fluid Mechanics. 1996;319:353-85. 
[28] Flores F, Garreaud R, Muñoz RC. Cfd simulations of turbulent buoyant atmospheric flows over complex geometry: Solver development in openfoam. Computers and Fluids. 2013;82:1-13.

[29] Moonen P, Dorer V, Carmeliet J. Effect of flow unsteadiness on the mean wind flow pattern in an idealized urban environment. Journal of Wind Engineering and Industrial Aerodynamics. 2012;104:389-96.

[30] Zhou B, Chow FK. Turbulence modeling for the stable atmospheric boundary layer and implications for wind energy. Flow, Turbulence and Combustion. 2012;88:255-77.

[31] Pieterse JE, Harms TM. Cfd investigation of the atmospheric boundary layer under different thermal stability conditions. Journal of Wind Engineering and Industrial Aerodynamics. 2013;121:82-97.

[32] Qu Y, Milliez M, Musson-Genon L, Carissimo B. Numerical study of the thermal effects of buildings on low-speed airflow taking into account $3 \mathrm{~d}$ atmospheric radiation in urban canopy. Journal of Wind Engineering and Industrial Aerodynamics. 2012;104:474-83.

[33] Kastner-Klein P, Rotach MW. Mean flow and turbulence characteristics in an urban roughness sublayer. Boundary-Layer Meteorology. 2004;111:55-84.

[34] Franke J, Hellsten A, Schlünzen H, Carissimo B. Best practice guideline for the cfd simulation of flows in the urban environment. Quality Assurance And Improvement of Microscale Meteorological Models ; 2007.

[35] Latif MT, Dominick D, Ahamad F, Khan MF, Juneng L, Hamzah FM, et al. Long term assessment of air quality from a background station on the malaysian peninsula. Science of the total environment. 2014;482:336-48.

[36] Harun Z, Reda E, Zulkifli R. Buoyancy effect on atmospheric surface layer: Measurements from the east coast of malaysia. The 15th Asian Congress of Fluid Mechanics; 2016.

[37] Issa RI. Solution of the implicitly discretised fluid flow equations by operatorsplitting. Journal of Computational Physics. 1986;62:40-65.

[38] Aristodemou E, Bentham T, Pain C, Colvile R, Robins A, ApSimon H. A comparison of mesh-adaptive les with wind tunnel data for flow past buildings: Mean flows and velocity fluctuations. Atmospheric Environment. 2009;43:623853.

[39] Rusdin A. Computation of turbulent flow around a square block with standard and modified $\mathrm{k}-\varepsilon$ turbulence models. International Journal of Automotive and Mechanical Engineering. 2017;14:3938-53.

[40] Xie Z-T, Castro IP. Large-eddy simulation for flow and dispersion in urban streets. Atmospheric Environment. 2009;43:2174-85.

[41] Gu Z-L, Zhang Y-W, Cheng Y, Lee S-C. Effect of uneven building layout on air flow and pollutant dispersion in non-uniform street canyons. Building and Environment. 2011;46:2657-65.

[42] Zaki SA, Hagishima A, Tanimoto J, Ikegaya N. Aerodynamic parameters of urban building arrays with random geometries. Boundary-Layer Meteorology. 2011;138:99-120.

[43] Rotach MW. Profiles of turbulence statistics in and above an urban street canyon. Atmospheric Environment. 1995;29:1473-86.

[44] Hutchins N, Chauhan K, Marusic I, Monty J, Klewicki J. Towards reconciling the large-scale structure of turbulent boundary layers in the atmosphere and laboratory. Boundary-Layer Meteorology. 2012;145:273-306. 